\title{
The Need for Not-So-White-Papers
}

JOSE L.S. GAMEZ

University of North Carolina Charlotte

\section{ANDREW CHIN}

Florida A\&M University

\begin{abstract}
Working under the title of "The Need for Not-So-White Papers: Architectural Education, Talk + Actions," we aimed for a dynamic discussion to be spurred by short presentations by invited speakers and guests. This was not a traditional session so no formal papers were presented, no slides were used, and we all sat face to face in good ole analog fashion. The format that we envisioned allowed audience members to participate and contribute to a meaningful dialog. Panelists included faculty and participants from ACSA programs in HBCU, HSI and PWI campuses as well as public and private educational environments. Specifically, we aimed to address the fact that architecture schools struggle to attract, retain and graduate under-represented minorities, which (in turn) limits the academy's ability to energize the profession.
\end{abstract}

What follows below is not a tradional paper but it helps capture some of the ideas that framed our session in Palo Alto.

\section{INTRODUCTION}

In 2008, José co-authored a chapter in the book Expanding Architecture. This was published over a decade after several ACSA focus sessions on diversity in architecture and after the ACSA Boston "Diversity in Architectural History" reader was produced by Diane Ghirardo, Barbara Allen, and Howard Smith (this is something that I am working to scan and add to our an online file--see below). Ghirado, of course, famously asked if "Can Architects be Socially Responsible" in 1991. The essay that I coauthored with Susan Rogers proclaimed that "an architecture of change" was needed-one that could engage a range of "political forces that shape theories, practices, academies, policies, and communities" (Gámez and Rogers 2008, 18-19). In many ways, we were suggesting that working to address the needs of marginalized communities required a political choice involving real and imagined geographies-both physical places and spatial knowledge.

A decade later, things haven't changed much; as Diana Budds of Fastcompany recently stated in her online article titled "Free Architecture School? Its Not As Crazy as it Sound,"

"When it comes to diversity in architecture, the statistics are jarring. For instance, African-Americans comprise $12 \%$ of the U.S. population, but only $2 \%$ of registered architects-a statistic that hasn't budged since the 1970s. Women make up only about $25 \%$ of the profession. Economic diversity is also a problem with tuition soaring as high as $\$ 60,000$; the average student graduates with $\$ 40,000$ in debt according to the American Institute of Architecture students."

What these statistics point to is the fact that diversity itself is a diverse topic: ranging from race to ethnicity, gendered norms to non-binary needs, various forms of visible and "invisible" abilities, and to questions of affluence, accessibility and social mobility, the topic of diversity in design disciplines is one that must be coupled with questions of design practice and education. Design and diversity must be studied and practiced together. In doing so, attention can be paid to the unintended consequences of architectural and design thinking, which, by extension, can help mitigate lingering forces of marginalization.

If we (architectural educators) are to address such complex challenges, then we must actively choose the space of the academy as a strategic location from which transform all other social spaces simultaneously (to paraphrase Ed Soja). This requires that we position schools of architecture as venues of sociopolitical action. Academic worlds are such by definition; they are liminal spaces through which people pass and arbiters of culture and taste; as such, they offer unique lenses through which the operations of power can be viewed and mitigated/ redirected in ways that produce new publics, new spaces, and new forms of knowledge.

\section{NOT SO WHITE PAPERS}

For this conference, we (me, Andrew Chin-Florida A\&M University, Robert Gonzalez-Texas Tech El Paso, and Michelle Reinhart-Georgia Tech) aimed to prompt a discussion by outlining a few things shaping our programs, which represent a range of campus environments: GA Tech is a public school with a national profile, Florida A\&M is an HBCU, Texas Tech's El Paso center is predominantly minority (Latino/a), and UNC Charlotte is a growing regional state school serving population made up of a significant proportion of first generation, pell eligible, and non-traditional students (I should point out that two other scholars were unable to accept our invitations: Susan Rogers from the University of Houston and Geraldine Forbes Isais from the University of New Mexico). 
With this session, our hope was to begin a conversation between faculty at various architectural programs that can foster what Berkeley sociologist Michael Burawoy calls an organic set of practices that build upon local knowledge in ways that are thick rather than thin. For Burawoy, "the publics addressed by traditional sociology (in our case, traditional architectural education) are broad, thin, passive" $(2009,193)$. This is knowledge production aimed at academic peers, often for disciplinary or proprietary reasons, that falls into the trap of thinness by domesticating questions of power in service of decontextualized audiences. In order to avoid the thin, we must develop "intense and mutually constitutive interaction" with the local (Burawoy 2008, 342). If our goal is less talk and more action, then we must begin by asking:

- For whom is architectural knowledge produced and for what purpose?

- How can the discipline and profession of architecture attract, retain and graduate under-represented minorities?

- What are the tools, strategies, support systems, curricular structures, or cultural skills needed to address the challenges you, your faculty, your students, and the local profession face each day?

- How can architectural programs strategically use their resources to advance an inclusive, diverse and equitable environment for faculty, staff and students?

To that end, we invited conference attendees to our NotSo-White Papers session, which did not feature formal presentations. We convened around a large table, face to face, and without slides-old school and analog.

And, I opened the conversation with a discussion of a few things shaping UNC Charlotte at this particular moment in time (see below). The aim was to provoke conversations about how architecture can become a vital voice as we navigate our current demographic contexts. Specifically, we aimed to address the fact that architecture schools struggle to attract, retain and graduate under-represented minorities, which (in turn) limits the academy's ability to energize the profession. Given this context, this paper is not a traditional paper. It is a second step in moving our collective conversation forward. To that end, this paper and other resources (handouts from the session, for example) can be found here: https://drive.google. com/drive/folders/1nj-ReW4N9doDf9sVidguOWFWwGbm5E LG? usp=sharing.

You are urged to contribute, to add resources, add text to this essay, and help us move this discussion forward towards actions.

\section{UNC CHARLOTTE. UNIVERSITY OF ACCESS?}

UNC Charlotte sees describes its mission on its website as "driven by the idea to provide opportunity and access to the intellectual capital that has helped build one of the nation's most vibrant regions." The key word here is access and its first iterations addressed the campus' founding as a place for returning WWII GIs to get an education. And, more recently, this is part of the university's response to, among many things, Latina/o migrations into Southern states that represent a challenge to a Black/White binary that has long characterized the region. For example, the southeastern US has experienced some of the county's most explosive Latina/o booms in the years between the 1990 and 2005 during which Latina/o demographic growth rose into the triple digits: $394 \%$ in North Carolina alone. Ironically, this geo-demographic set of shifts are occurring in an era of presidential tweets equating social division with national security, when Black, Brown, and a wide range of lives don't matter, and as our educational and professional environments face the "complex nature of race relations in a post-civil rights era" (Omi 1993, 9).

As a university of access, our demographics present interesting opportunities and challenges: in 2018, over $50 \%$ of UNC Charlotte's students are Pell eligible and over $70 \%$ received financial aid; $27 \%$ of all incoming freshman were 1 st generation college attendees; and 93\% are from North Carolina.

A few more stats: Between 2013 and 2018, UNC Charlotte has increased diversity in its undergraduate population by:

- 2013: 62\% Caucasian, 17\% African America, 7\% Hispanic, 5\% Asian, 3\% multi-racial; Gender: \% women vs 52\% men.

- 2018: 57\% Caucasian, 16\% African American, 10\% Hispanic, 7\% Asian, and 5\% multi-racial; Gender: 46.7\% women vs 53.3 men.

Progress, by some measures, right? Our School of Architecture, for comparison, in fall 2018:

- 66\% Caucasian, 12\% African American, 10\% Hispanic, 5\% Asian, $4 \%$ multi-racial, and $60 \%$ female vs $40 \%$ male

One of the challenges our SoA faces is an unfortunate need to manage enrollment beginning with the freshman year. Our program has an enrollment model in which approximately 68 freshman and transfers are admitted each fall (we are working to bring this number up). This enrollment model is tied to two things: resources (we are at capacity in our building) and tradition (the SoA has had an interview requirement for the majority of his existence). The interview process, which is coupled with a required portfolio review, is a barrier for many potential students; we know this, in part, because most North Carolina schools do not have art programs or curricula, for example, from which a portfolio might be drawn. So, while over 500 students each fall express interest in architecture, only approximately 250 to 300 complete the secondary application and, of that group, only about 120 are invited to our interview events. We are making concerted efforts to reduce that barrier and this has led to a few strategies to develop a robust applicant pool: 
- We have an immersive Summer Design Academy (high school students live on campus for a week, take a "seminar" and a "studio" and develop material for a portfolio). This Academy is augmented by several scholarships aimed at need-based students from under-represented groups and rural areas.

- We have asked a long-time donor to reallocate their undergraduate scholarship: initially, it supported several undergraduate students with a \$1,000 award each (solicited annually); this scholarship was converted to a full in-state tuition award (4 years) for an incoming freshman who demonstrates financial need and academic excellence.

- We are implementing articulation agreements with several community colleges that will establish a pipeline from AA programs into our programs.

These efforts are geared to helping us develop a diverse and talented applicant pool. And, it is hoped that as students enroll then a critical mass of students will coalesce into supportive and mutually reinforcing communities. This is an issue that was raised by conference attendees: that establishing a welcoming climate requires that people see others like themselves among the students, faculty and staff. This can help signal that the school will be a supportive environment and it will spread the "cultural tax" across more shoulders-meaning that the (untended?) burden placed on students, faculty and staff of color to represent the views and values of their colleagues is minimized. This is a critical concern that was raised in our session and it was one that resonated with (I believe) everyone in the room.

\section{FLORIDA A\&M UNIVERSITY. HBCU DIVERSITY?}

The challenge of inclusion, diversity and equity are not limited to Predominantly White Institutions (PWIs), which make up many state university systems like the one that includes University of North Carolina Charlotte. These challenges are also at the center of conversations at Historically Black Colleges and Universities (HBCUs) like Florida A\&M. Since the first HBCUs were founded, before the American Civil War to provide black youths access to a basic education, HBCUs have played a significant role in the educational attainment and construction of a black middle class.

According to the Brookings Institution (https://www.brookings. edu/blog/the-avenue/2017/11/21/black-colleges-can-reviveamerican-cities/), HBCUs "serve just 0.1 percent of the overall student population, but account for 20 percent of black students who complete bachelor's degrees." Similarly, the US DOE indicates that "HBCUs have provided undergraduate training for three fourths of all black persons holding a doctorate degree; three fourths of all black officers in the armed forces; and four fifths of all black federal judges." In architecture, the NAAB 2017 Report on Architecture Education at MinorityServing Institutions indicates that the HBCUs produce $32 \%$ of the degrees awarded to African American students in architecture.

While these HBCUs have a significant purpose, they still face the challenge of recruiting, enrolling and graduating students of color to architecture. Except, at these schools, graduating black student is not optional. To meet their professional, institutional and historical mission, multiple strategies are implemented.

- Admission - The National Center for Fair and Open Testing, a nonprofit known as FairTest, recently analyzed SAT scores for the high school class of 2019. It reported that the gaps between demographic groups grew larger from a year earlier, with the average scores of students from historically disenfranchised groups falling further behind students from more privileged families. While a record number of colleges drop SAT/ACT admissions requirement amid growing disenchantment with standardized tests, architecture programs often rely upon additional admissions requirements. For example, many schools still hold on to the "need" of a portfolio review as filter as José pointed out earlier. In contrast to most schools, none of the HBCU programs require a portfolio for freshman admission or for 3rd year advancement (no internal "gate'). Changes in who enrolls and graduates may require an honest discussion about a school's selfimposed institutional barriers.

- Faculty - While most PWI NAAB schools argue that they can not find black faculty, it does not seem to be an issue at Minority Serving Institutions (MSIs). The 2018 NAAB Report on Architecture Education at Minority-Serving Institutions indicates that faculty at MSIs represent 23\% of the total number of Black or African American faculty in all NAAB-accredited programs. The solution may be found in the practices of non-architecture programs who recruit future black faculty at HBCUs. According to the US DOE, "Fifty percent of black faculty in traditionally white research universities received their bachelor's degrees at an HBCU." Changes in faculty appointments will require honest discussions about the implicit bias toward certain schools as the source for faculty.

- Summer Classes - Most architecture programs expect students to use their summers for internships. But, not all architecture students have the same high school preparation and bring different strengths and challenges to their freshman experience. At FAMU, some freshman are directed to defer their freshman studio and initially focus on their general education requirements. For these students, the freshman studio is offered every summer. The studio is not a filter that determines who can or cannot be in the program; instead, it is a mechanism to keep students on their 4 year plan. Changes in who enrolls and graduates may require schools to reconsider when courses are offered. 
- Studio Schedule - In non-architecture programs, a 3 credit class meets for 3 hours each week and sections are offered at various times or days of the week. The student centered schedule accommodates students that work, student athletes, students with day-care and others needs. In architecture, a 4 or 5 credit studio meets for 9-12 contact hours each week and is only scheduled for MWF afternoons. At Morgan State University, an HBCU in Baltimore, design studio is offered at night so students can work in the day. At FAMU, summer studios allow student athletes to stay in their preferred major. Changes in who enrolls and graduates may require schools to reconsider their traditions that define who does vs does not belong in architecture studios and how and when those studios should be offered.

No one questions the role of culture in shaping design decision making. It informs the materials selected (and not selected), the environmental conditions considered (and not considered) and who architecture serves. But, top many programs minimize the culture "of architecture education" as if it doesn't play a role in the impacts that the inherent biases embedded in architectural culture may have upon who is (and who is not) part of the discipline. If architectural educators are serious about changing who architecture serves, we may want to periodically put tradition on the shelf and give some attention to the cultural lives of our students.

\section{CONCLUSIONS?}

The cases described above point to both modest steps and larger questions that must be addressed if we are to move from talk to action (as the conference demanded). As Thomas Dutton (1991) has pointed out, all curricula have hidden or "unstated values, attitudes, and norms which stem tacitly from the social relations of the school and classroom as well as the content of the course." If we view the core of an architectural curriculum to be the design studio as did Dutton, then the hidden curriculum reenforces "individuality, competition, student dependency on a dominant faculty member."

There are instructive models of educational and professional practice in other disciplines that may be helpful in this regard. For example, Burawoy's Public Sociology and its emphasis upon deep engagements with the local provides a critical model for publicly engaged scholarship within the academy. This is a mode of local knowledge production that not only helps activate counterpublics (answers the question, for whom?) but also aims to create lasting change within local lived spaces (answers the question, for what purpose?).

Certainly, Burawoy's work will not translate directly to all modes of architectural education but the intent of a publicfacing professional set of practices can. And, this is one way that our discipline and profession can begin attract, retain and graduate under-represented communities. In this sense, architectural education must address "questions, problems and issues of public significance" while repositioning "the purposes of research as public or civic rather than disciplinary or proprietary" (Latham 2003, 2-3). If architectural education moved in such a direction, it would begin to address a question of relevance that is increasingly important to college-age people of all groups--and often of particular importance to traditionally underrepresented communities.

Rethinking the format, time/schedule and foci of design studios is also a potential strategy that can help architectural programs strategically use their resources to advance an inclusive, diverse and equitable environment for faculty, staff and students. As research has illustrated, opportunities to work in settings that have purpose and relevace to larger societal contexts are particularly valuable for underrepresented students; such engagements through, for example, research and mentorship lead to interactions with faculty members that can have positive impacts on student decisions to pursue graduate education - that is the gateway to the professoriate. And such opportunities combat the many documented circumstances in which minority students report feelings of isolation, invisibility and a distancing from faculty. In many ways, rethinking many of our own practices will lead to larger cultural frameworks, support systems, curricular structures needed to address the challenges we (Andrew, José, you, your faculty, your students, and local professionals) face each day.

\section{REFERENCES}

Budds, D. "Free Architecture School? It's Not as Crazy as it Sounds" online at Fastcompany.com (0209-17): https://www.fastcompany.com/3067656/ free-architecture-school-its-not-as-crazy-as-it-sounds

Blackwell, E., and Pinder, P. (2014). What are the motivational factors of first-generation minority college students who overcome their family histories to pursue higher education? Coll. Stud. J. 48, 45-56.

Burawoy, M. Public Sociology in the Age of Obama. Innovation-The European Journal of Social Science Research, Vol. 22, No. 2 (June 2009) 189-199.

Cantor, N. Academic Excellence and Civic Engagement: Constructing a Third Space for Higher Education. Baylor University's Presidential Inaugural Lecture Series, Waco, TX, December 7, 2010. Available online: http://www.syr.edu/chancellor/speeches/Baylor_final.pdf.

Cherng, H., Turney, K., and Kao, G. (2014). Less socially engaged? Participation in friendship and extracurricular activities among racial/ethnic minority and immigrant adolescents. Teach. Coll. Rec. 
Dutton, T. "The Hidden Curriculum and the Design Studio: Toward a Critical Studio Pedagogy" in Voices in Architectural Education: Cultural Politics and Pedagogy (New York: Bergin and Garvey, 1991). 65-194.

Gámez, J. and S. Rogers. Introduction: An Architecture of Change. B. Bell \& K. Wakeford, eds. Expanding Architecture: Design As Activism (New York: Metropolis Books, 2008) 18-25.

Ghirardo, D. "Can Architects be Socially Responsible?" in Out of Site: A Social Criticism of Architecture, edited by Diane Ghirado (Seattle: Bay Press, 1991. 27-45.

Kenny, S. S. et al. Reinventing Undergraduate Education: A Blueprint for America's Research Universities. Stony Brook, N.Y.: State University of New York at Stony Brook, 1998.

Latham, A. Liberal Education for Global Citizenship: Renewing Macalester's Traditions of Public Scholarship and Civic Learning." Occasional Paper sponsored by Project Pericles, Macalester College, 2003. Available Online: http://www. macalester.edu/pericles.

Omi, M. "Out of the Melting Pot and Into the Fire: Race Relations Policy," in Policy Issues to the Year 2020: The State of Asian Pacific America-A Public Policy Report (Los Angeles: LEAP Asian Pacific American Public Policy Institute/UCLA Asian American Studies Center, 1993).

Padilla, A. "The 'Cultural Taxation' of Faculty of Color in the Academy." California Faculty Association Magazine (fall 2013): https://www.calfac.org/magazine-article/ cultural-taxation-faculty-color-academy

Soja, E. Thirdspace: Journeys to Los Angeles and Other Real and Imagined Places (Cambridge, MA: Blackwell, 1996).

Tauke, E., K. Smith, and C. Davis, Diversity and Design (New York: Routledge, 2016).Burawoy, M. Public Sociology in the Age of Obama. Innovation-The European Journal of Social Science Research, Vol. 22, No. 2 (June 2009) 189-199.

Cantor, N. Academic Excellence and Civic Engagement: Constructing a Third Space for Higher Education. Baylor University's Presidential Inaugural Lecture Series, Waco, TX, December 7, 2010. Available online: http://www.syr.edu/chancellor/speeches/Baylor_final.pdf.

Cherng, H., Turney, K., and Kao, G. (2014). Less socially engaged? Participation in friendship and extracurricular activities among racial/ethnic minority and immigrant adolescents. Teach. Coll. Rec.

Dutton, T. "The Hidden Curriculum and the Design Studio: Toward a Critical Studio Pedagogy" in Voices in Architectural
Education: Cultural Politics and Pedagogy (New York: Bergin and Garvey, 1991). 65-194.

Gámez, J. and S. Rogers. Introduction: An Architecture of Change. B. Bell \& K. Wakeford, eds. Expanding Architecture: Design As Activism (New York: Metropolis Books, 2008) 18-25.

Ghirardo, D. "Can Architects be Socially Responsible?" in Out of Site: A Social Criticism of Architecture, edited by Diane Ghirado (Seattle: Bay Press, 1991. 27-45.

Kenny, S. S. et al. Reinventing Undergraduate Education: A Blueprint for America's Research Universities. Stony Brook, N.Y.: State University of New York at Stony Brook, 1998.

Latham, A. Liberal Education for Global Citizenship: Renewing Macalester's Traditions of Public Scholarship and Civic Learning." Occasional Paper sponsored by Project Pericles, Macalester College, 2003. Available Online: http://www. macalester.edu/pericles.

Omi, M. "Out of the Melting Pot and Into the Fire: Race Relations Policy," in Policy Issues to the Year 2020: The State of Asian Pacific America-A Public Policy Report (Los Angeles: LEAP Asian Pacific American Public Policy Institute/UCLA Asian American Studies Center, 1993).

Padilla, A. "The 'Cultural Taxation' of Faculty of Color in the Academy." California Faculty Association Magazine (fall 2013): https://www.calfac.org/magazine-article/ cultural-taxation-faculty-color-academy

Soja, E. Thirdspace: Journeys to Los Angeles and Other Real and Imagined Places (Cambridge, MA: Blackwell, 1996).

Tauke, E., K. Smith, and C. Davis, Diversity and Design (New York: Routledge, 2016). 